\title{
Energetics of Sodium Transport in the Urinary Bladder of the Toad Effect of Aldosterone and Sodium Cyanide
}

\author{
Nadim Cortas, Elias Abras, May Arnaout, \\ Arshag Mooradian, and Samar Muakasah \\ Departments of Pharmacology and Medicine, American \\ University of Beirut, Beirut, Lebanon
}

bstract. Experiments were designed to determine whether the stimulatory effect of aldosterone on sodium transport involves an increase in tissue ATP. Urinary bladders that were removed from toads presoaked in $0.6 \%$ saline for $48-72 \mathrm{~h}$, mounted as sacs, and maintained in open circuit except for brief observation of short circuit current every 30 min responded to $100 \mathrm{nM}$ aldosterone added to the serosal bath with an increase in short circuit current to $170 \%$ of control hemibladders, which plateaus at 2-3 $\mathrm{h}$. Tissue $(\mathrm{ATP}) /(\mathrm{ADP}) \times\left(\mathrm{P}_{\mathrm{i}}\right)$ measured in perchloric acid extracts increased to a maximum of $208 \%$ of controls $(P<0.001)$ and ATP increased to $116 \%$ of controls $(P<0.01)$ at $180 \mathrm{~min}$. The short circuit current response to aldosterone paralleled the increase in ATP and $(\mathrm{ATP}) /(\mathrm{ADP}) \times\left(\mathrm{P}_{\mathrm{i}}\right)$ measured at 75,120 , 180 , and $240 \mathrm{~min}$. In bladders clamped at $-150 \mathrm{mV}$, the short circuit current response to aldosterone was greater: $280 \%$ of controls $(P<0.001)$ and tissue (ATP)/(ADP) $\times\left(P_{\mathrm{i}}\right)$ increased to $191 \%$ of controls $(P<0.001)$. In continuously short circuited bladders and bladders clamped at $+75 \mathrm{mV}$, the short circuit current response to aldosterone and the change in ATP, ADP, or $P_{i}$ were markedly diminished. $100 \mu \mathrm{M}$ amiloride added to mucosal bath decreased the short circuit current to zero and inhibited the short circuit current response to aldosterone, whereas tissue ATP increased to $141 \%(P<0.05) .100,250$, and

Dr. Muakasah's present address is University of Southern California, School of Medicine, Department of Pharmacology, Los Angeles, CA. Dr. Mooradian's present address is University of Minnesota, Department of Medicine, Minneapolis, MN. Address correspondence and reprint requests to Dr. Cortas, \% Dr. Walser, Johns Hopkins School of Medicine, Baltimore, MD 21205.

Received for publication 26 May 1983 and in revised form 29 September 1983.

J. Clin. Invest.

(c) The American Society for Clinical Investigation, Inc. 0021-9738/84/01/0046/07 \$1.00

Volume 73 , January $1984,46-52$
$500 \mu \mathrm{M} \mathrm{NaCN}$ dropped the short circuit current to 59 , 35 , and $24 \%$ of control values, respectively. Concurrently, tissue ATP measured at $60 \mathrm{~min}$ after the addition of $\mathrm{NaCN}$ dropped to 79,66 , and $56 \%$ of control values, respectively, and tissue ATP/ADP dropped to 68,50 , and $40 \%$, respectively. The data revealed significant correlation between the change in the rate of sodium transport produced by aldosterone or $\mathrm{NaCN}$ as measured by the short circuit current and the concentration of ATP $(r=0.96$, $P<0.001)$, as well as ATP/ADP $(r=0.95, P<0.001)$. In conclusion, these results support the view that the stimulatory effects of aldosterone on sodium transport involve an increase in ATP or $(\mathrm{ATP}) /(\mathrm{ADP}) \times\left(\mathrm{P}_{\mathrm{i}}\right)$.

\section{Introduction}

Aldosterone stimulates sodium transport across a variety of epithelial membranes including the toad bladder (1). The response requires protein synthesis and appears to be mediated by aldosterone-induced proteins (AIP) ${ }^{1}(2-5)$. The mechanism by which AIP facilitates sodium transport is not well understood. AIP may increase the permeability of the mucosal membrane to sodium, thereby indirectly facilitating the extrusion of sodium at the serosal surface of the epithelial cell (permease hypothesis) (6-8). The observed rise in intracellular sodium concentration $(6,7)$ and the fall in transepithelial electrical resistance $(8)$ are consistent with the permease hypothesis. However, Lipton and Edelman (9) showed no change in intracellular sodium concentration in response to aldosterone. Goodman et al. (10) found that aldosterone potentiated the subsequent effect of vasopressin on sodium transport in the absence of aerobic metabolism and oxidative phosphorylation. They proposed that aldosterone

1. Abbreviations used in this paper: AIP, aldosterone-induced protein; $\mathrm{PC}$, phosphocreatine; PD, potential difference; PDte/PDoe, ratio of PD at time $t$ to beginning of experiment for experimental groups; PDtc/ PDoc, ratio of PD at time $t$ to beginning of experiment for control groups; SCC, short circuit current; SCCte/SCCoe, ratio of SCC at time $t$ to beginning of experiment for experimental groups; SCCtc/SCCoc, ratio of SCC at time $t$ to beginning of experiment for control groups; TCA, tricarboxylic acid. 
stimulates sodium transport by increasing the activity and/or the number of $\mathrm{Na}-\mathrm{K}$ pumps. However, in vitro measurement of Na-K-ATPase in toad bladders that responded to aldosterone did not show a change in maximum velocity $\left(V_{\max }\right)$ or in Michaelis constant $\left(K_{\mathrm{m}}\right)$ for sodium and $\operatorname{ATP}(11,12)$ AT $^{32} \mathrm{P}(\gamma)$ sodium-dependent binding to mucosal homogenates of the toad bladder also failed to respond to aldosterone (13). Experiments in which tricarboxylic acid (TCA) cycle intermediates and inhibitors of mitochondrial NADH dehydrogenase were added to substrate-depleted bladders suggested that aldosterone-induced ATP generation underlies the mechanism of aldosterone action (13-16).

Aldosterone increased the activity of several TCA cycle enzymes, notably citrate synthase activity in toad bladder (17), accompanied by an increase in $\mathrm{NADH} / \mathrm{NAD}^{+}$ratio with a time course parallel to the change in urinary $\mathrm{Na}^{+} / \mathrm{K}^{+}(18,19)$. This increase in $\mathrm{NADH} / \mathrm{NAD}^{+}$enhances the formation of ATP by phosphorylation of ADP. Handler et al. (20) observed no significant change in the levels of ATP, ADP, and AMP, in bladders incubated with aldosterone for $15 \mathrm{~h}$, but phosphocreatine (PC) levels decreased and creatine levels increased significantly. The long incubation followed by mucosal cell scraping before freezing may alter the nucleotide levels.

We have reported elsewhere that both ATP and (ATP)/ $(\mathrm{ADP}) \times\left(\mathrm{P}_{\mathrm{i}}\right)$ are increased in turtle bladder mucosal sacs exposed to aldosterone $(21,22)$. In the present study, ATP, ADP, and $P_{i}$ were measured in freshly mounted hemibladders at different times after the onset of aldosterone action in open circuit and also at $180 \mathrm{~min}$ while clamped at different potentials. In addition, ATP and ADP were measured 60 min after the addition of 100 $\mu \mathrm{M}, 250 \mu \mathrm{M}$, and $500 \mu \mathrm{M} \mathrm{NaCN}$ and 180 min after addition of $100 \mathrm{nM}$ aldosterone in amiloride-treated hemibladders. The nucleotide levels were correlated with the short circuit current.

\section{Methods}

Large female toads (Bufo marinus), obtained from Mogul Ed Co., Oshkosh, WI, were kept for a maximum of $5 \mathrm{wk}$, being force-fed once per week with dog food. For 2-3 d before the experiment, they were soaked in $0.6 \% \mathrm{NaCl}$ solution to decrease endogenous aldosterone secretion (1). The abdomen was opened and the blood replaced by amphibian Ringer's solution ( $111 \mathrm{mM} \mathrm{NaCl}, 3 \mathrm{mM} \mathrm{NaHCO}{ }_{3}, 2.7 \mathrm{mM} \mathrm{CaCl}_{2}, 3.4$ $\mathrm{mM} \mathrm{KCl}$, and $2 \mathrm{mM} \mathrm{MgCl}_{2}, \mathrm{pH}$ 7.6) perfused through the aorta and drained from a cut in the liver. When all the blood was cleared from the hemibladders, these were dissected out, rinsed, and immediately mounted as sacs on glass cannulae as described previously $(23,24)$. Potential difference (PD) and short circuit current were measured as described by Ussing and Zerhan (25). Bladders that failed to develop a PD of $60 \mathrm{mV}$ or more were discarded. 10 groups of experiments were performed. In Group I, bladders were maintained in open circuit, except for 5-s intervals every 30 min during which the short circuit current was recorded. Once the PD and short circuit current were stable for 30 min, aldosterone was added to a final concentration of $100 \mathrm{nM}$ in the serosal bath of one hemibladder. To the other hemibladder, methanol, the diluent for aldosterone, was added in the same amount. PD and short circuit current, recorded just before the additions, were called
PDoe and short circuit current (SCC)oe for aldosterone-treated hemibladders and PDoc and SCCoc for control hemibladders. The experiment was terminated at $75 \mathrm{~min}$ (i.e., after the onset of stimulation was definitely observed), 120, 180, and $240 \mathrm{~min}$ in different subgroups of experiments. The PD and short circuit current at different times are called PDte and SCCte for hemibladders treated with aldosterone and PDtc and SCCtc for control hemibladders. In group II, the hemibladders were clamped continuously at $-150 \mathrm{mV}$ (mucosa negative). In group III, the hemibladders were clamped continuously at $0 \mathrm{mV}$. In Group IV, the hemibladders were clamped continuously at $+75 \mathrm{mV}$ (mucosa positive). In group $\mathrm{V}$, the hemibladders were clamped at their own spontaneous potential. In groups II, III, IV, and V the spontaneous PD and short circuit current were measured for periods of $5-10 \mathrm{~s}$ every $30 \mathrm{~min}$. In Group VI, amiloride in a final concentration of $100 \mu \mathrm{M}$ was added to both hemibladders, the short circuit current dropped to zero, $100 \mathrm{nM}$ aldosterone was added to the serosal side of one hemibladders and methanol to the other. All experiments in group II to VI were terminated at $180 \mathrm{~min}$. In groups VII, VIII, and IX, $100 \mu \mathrm{M}, 250 \mu \mathrm{M}$, and 500 $\mu \mathrm{M} \mathrm{NaCN}$ was added, respectively, to the serosal bath. The three concentrations of $\mathrm{NaCN}$ were chosen to drop the short circuit current by $\sim 25,50$, and $75 \%$, respectively. In group $\mathrm{X}, 100 \mathrm{nM}$ aldosterone and $100 \mathrm{nM}$ prednisolone were added to the serosal bath of each hemibladder. In Groups VII to IX, the experiments were terminated $60 \mathrm{~min}$ after the addition of $\mathrm{NaCN}$, and in Group $\mathrm{X}, 150 \mathrm{~min}$ after the addition of aldosterone and prednisolone. In all groups the hemibladders were then quickly emptied and freeze-clamped between two aluminum blocks previously soaked in liquid nitrogen. Extraction by perchloric acid and measurement of ATP, ADP, and $P_{i}$ were done as described by Fawaz and Fawaz (26); $P_{i}$ was measured colorimetrically $(26,27)$. The protein precipitated by the perchloric acid was measured by the biuret method (28).

\section{Results}

The short circuit current and PD responses to $100 \mathrm{nM}$ aldosterone in the groups I to IV are shown in Figs. 1 and 2, respectively. Each point reflects the mean \pm SEM. The short circuit current responses in group V did not differ from Group I. The observed short circuit current and PD response to aldosterone was largest in the bladders clamped at $-150 \mathrm{mV}$. The mean rise of short circuit current relative to control ([SCCte/SCCoe]/ [SCCtc/SCCoc] $)$ at $180 \mathrm{~min}$ was $2.85 \pm 0.30(P<0.01)$, and that of (PDte/PDoe)/(PDtc/PDoc) was $1.40 \pm 0.05(P<0.01)$.

In the open circuit mode, the response to short circuit current followed the same pattern as the response at $-150 \mathrm{mV}$, but the peak value was significantly lower, with (SCCte/SCCoe)/(SCCtc/ SCCoc) ratio of $1.72 \pm 0.008(P<0.01)$; and (PDte/PDoe)/(PDtc/ PDoc) ratio of $1.20 \pm 0.03(P<0.01)$.

The response was markedly diminished and not significant up to $180 \mathrm{~min}$ for either short circuit current or PD when bladders were clamped at 0 or $+75 \mathrm{mV}$ (Figs. 1 and 2).

In bladders kept at their spontaneous PD, (ATP)/(ADP) $\times\left(\mathrm{P}_{\mathrm{i}}\right)$ was observed to increase to $138 \%$ of controls at $75 \mathrm{~min}$ $(P<0.05)$ reaching $208 \%$ of controls at $180 \mathrm{~min}(P<0.001)$ and then declined to $142 \%$ of controls at $240 \mathrm{~min}$ (Fig. 3). ATP increased while ADP and $P_{i}$ decreased as shown in Table $I$. ATP/ADP increased to $113,123,143$, and $129 \%$ of controls at 


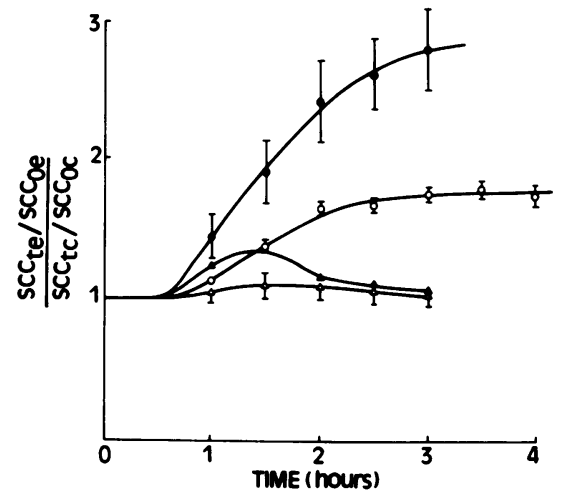

Figure 1. Short circuit current response to aldosterone $100 \mathrm{nM}$ with time in toad bladders kept in open circuit $(O)(n=37)$, clamped at $-150 \mathrm{mV}(\bullet)(n=11)$, clamped at $0 \mathrm{mV}(\Delta)(n=13)$, and clamped at $+75 \mathrm{mV}(\Delta)(n=6)$; mean \pm SEM.

$75,120,180$, and $240 \mathrm{~min}$, respectively. The various changes of the phosphate compound levels under conditions of different clamped potentials at $180 \mathrm{~min}$ after the addition of aldosterone are shown in Table II. The hemibladders clamped at $-150 \mathrm{mV}$ had significant increase in the ATP as well as (ATP)/(ADP) $X\left(P_{i}\right)$ (Fig. 4$)$ in the aldosterone treated as compared with the control hemibladders with a mean percentage increase to $117 \%$ of controls for ATP $(P<0.01)$ and $191 \%$ of controls for (ATP)/ $($ ADP $) \times\left(P_{i}\right)(P<0.001)$.

In bladders kept in open circuit or clamped at their spontaneous PD, similar but smaller changes were seen. In depolarized and reversed polarized bladders, no significant changes were seen (Table II and Fig. 4).

The short circuit current decreased to $10 \%$ after the addition of $100 \mu \mathrm{M}$ amiloride to the mucosal bath. There was no change

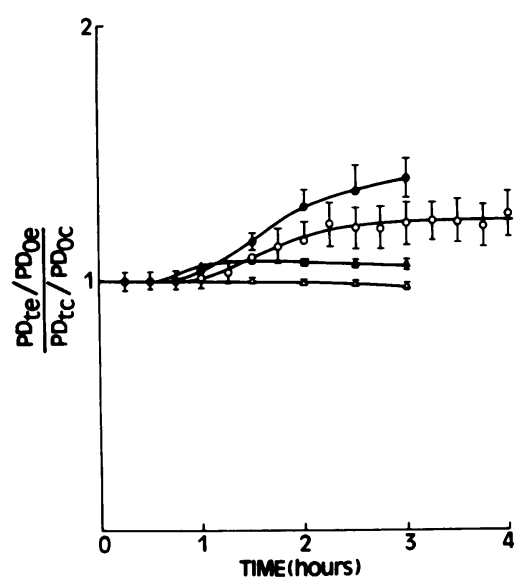

Figure 2. The potential difference response to $100 \mathrm{nM}$ aldosterone with time in toad bladders kept in open circuit $(O)(n=37)$, clamped at $-150 \mathrm{mV}(\bullet)(n=11)$, clamped at $0 \mathrm{mV}(\Delta)(n=13)$, and clamped at $+75 \mathrm{mV}(\Delta)(n=6)$; mean \pm SEM.

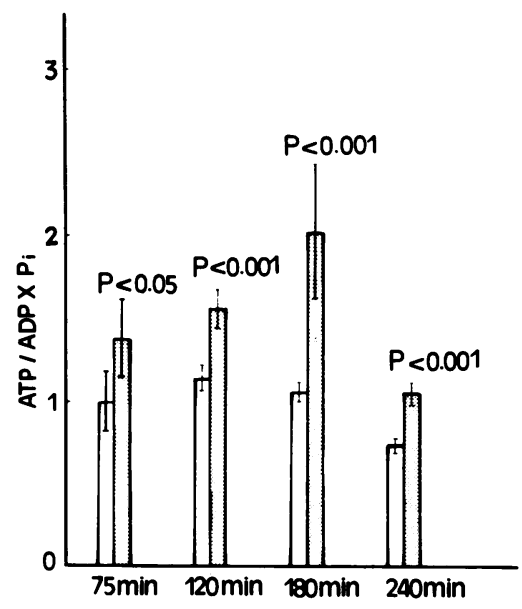

Figure 3. (ATP)/(ADP) $\times\left(\mathrm{P}_{\mathrm{i}}\right)$ in control hemibladders (clear bars) and those treated with aldosterone (dotted bars) measured at $75 \mathrm{~min}$ $(n=6), 120 \mathrm{~min}(n=11), 180 \mathrm{~min}(n=15)$, and $240 \mathrm{~min}(n=10)$ in open circuit. Vertical bars represent SEM.

in short circuit current after $100 \mathrm{nM}$ aldosterone in amiloridetreated hemibladders. However, ATP increased to $141 \%$ in these hemibladders. ATP decreased to 79,66 , and $56 \%$ of controls after the addition of 100,250 , and $500 \mu \mathrm{M} \mathrm{NaCN}$, respectively, while ATP/ADP decreased to 67,50 , and $40 \%$, respectively. These were associated with similar changes in short circuit current and PD as shown in Figs. 5 and 6, respectively. Figs. 7 and 8 show the variation in the short circuit current concomitant with the changes in ATP and ATP/ADP. In open circuit whether after inhibition by $\mathrm{NaCN}$ or stimulation by aldosterone, the changes in ATP or ATP/ADP are proportional to the changes in the short circuit current $(r=0.96, P<0.001$ for ATP and $r=0.95, P<0.001$ for ATP/ADP).

\section{Discussion}

The increase in short circuit current after aldosterone administration was observed at $75 \mathrm{~min}$ and reached a peak level at $180 \mathrm{~min}$ in open circuit bladders. The increase was correlated with changes in ATP and $(\mathrm{ATP}) /(\mathrm{ADP}) \times\left(\mathrm{P}_{\mathrm{i}}\right)$. In bladders clamped at $-150 \mathrm{mV}$, the magnitude of the change in the nucleotide levels and short circuit current in response to aldosterone was more than in open circuit bladders at $180 \mathrm{~min}$, whereas the changes in nucleotide levels and short circuit current in response to aldosterone were markedly diminished at 0 and $+75 \mathrm{mV}$ and not significant up to $180 \mathrm{~min}$. This may seem at variance with results of other investigators $(29,30)$. Porter and Edelman (29), under similar conditions using continuously short-circuited freshly mounted diaphragms, showed that the response to aldosterone was markedly diminished, if not absent. However, under different experimental conditions, short circuit current response to aldosterone varied significantly. Overnight 
Table I. Mean Values for Adenine Nucleotides and $P_{i}$ of Control $(C)$ and Aldosterone-treated $(E)$ Hemibladders at Different Times

\begin{tabular}{|c|c|c|c|c|c|c|}
\hline \multirow[b]{2}{*}{ Time } & \multicolumn{2}{|c|}{ ATP* } & \multicolumn{2}{|c|}{ ADP* } & \multicolumn{2}{|c|}{$P_{i}^{*}$} \\
\hline & $\mathrm{C}$ & E & C & $\mathrm{E}$ & C & $\mathbf{E}$ \\
\hline $75 \mathrm{~min}$ & $0.98 \pm 0.01$ & $1.01 \pm 0.04$ & $0.59 \pm 0.05$ & $0.53 \pm 0.04$ & $1.86 \pm 0.13$ & $1.51 \pm 0.11$ \\
\hline $120 \mathrm{~min}$ & $0.88 \pm 0.02$ & $0.94 \pm 0.02 \ddagger$ & $0.53 \pm 0.04$ & $0.46 \pm 0.04$ & $1.58 \pm 0.14$ & $1.39 \pm 0.13$ \\
\hline $180 \mathrm{~min}$ & $0.87 \pm 0.03$ & $1.03 \pm 0.03 \S$ & $0.51 \pm 0.03$ & $0.42 \pm 0.02 \S$ & $1.72 \pm 0.12$ & $1.44 \pm 0.16$ \\
\hline $240 \mathrm{~min}$ & $0.91 \pm 0.02$ & $1.05 \pm 0.03 \S$ & $0.65 \pm 0.02$ & $0.58 \pm 0.02 \S$ & $1.94 \pm 0.21$ & $1.84 \pm 0.12$ \\
\hline
\end{tabular}

* Values are expressed as micromoles per $100 \mathrm{mg}$ proteins. $\ddagger$ Significantly different from control values $P<0.05$. $\S$ Significantly different from control values $P<0.01$.

incubation in aldosterone-free media followed by substrate repletion produced a highly responsive and reproducible system (28). This could be the result of ionic changes or an increase in the amino acid pool available for AIP formation. Soaking the toads in different concentrations of saline and for variable periods of time results in varying responsiveness to aldosterone $(1,31,32)$. Whether this is due to variable concentrations of aldosterone in the serum and tissues or changes in ionic concentrations remains controversial. Our results show that the response of the short circuit current and PD to $100 \mathrm{nM}$ aldosterone is potential dependent. Estimated sodium flux through the active transport pathway has been reported to be decreased by hyperpolarization and increased by depolarization or reversed polarization going from $0.14 \mu \mathrm{A} / \mathrm{mg}$ at $-150 \mathrm{mV}$ to $2.66 \mu \mathrm{A} /$ $\mathrm{mg}$ at $+75 \mathrm{mV}$ (24). Furthermore, depolarization increased the "transport pool" of sodium defined as the quantity of sodium within the epithelium labeled by radioactive sodium from the mucosal medium (33). Toad bladder epithelial cell swelling indicating increased cellular sodium was observed when the potential was reversed to $+50 \mathrm{mV}(34)$. All the above evidence indicates that the rate of transport is increased by depolarization, which would imply that the rate of ATP hydrolysis required

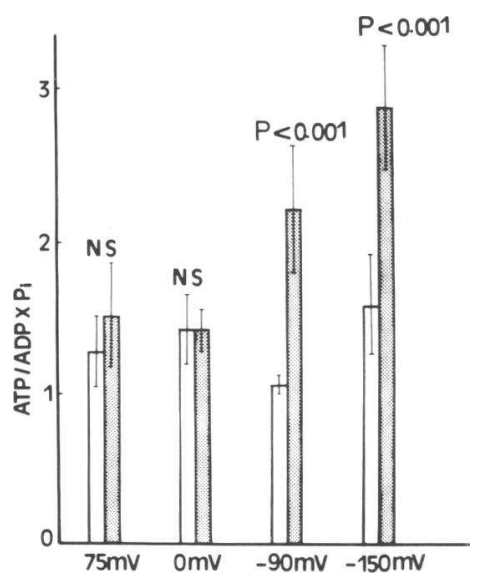

Figure 4. (ATP)/(ADP) $\times\left(P_{i}\right)$ in control hemibladders (clear bars) and those treated with aldosterone (dotted bars) clamped at $+75 \mathrm{mV}(n$ =6), $0 \mathrm{mV}(n=13)$, in open circuit $-90 \pm 6 \mathrm{mV}(n$ $=15)$ and at $-150 \mathrm{mV}(n$ $=11$ ) measured at 180 $\min$. for such transport would also increase, and this implication is strongly supported by the observation that oxygen consumption is also increased by depolarization (35). Yet, despite the fact that there may be pronounced changes in the rate of transport and ATP hydrolysis with shifts in the voltage, we observed no change in the level of ATP, or in the (ATP)/(ADP) $\times P_{i}$ ratio. This would mean that the ATP-utilizing system (transport) is so tightly coupled to the ATP-generating system (respirationoxidative phosphorylation) that scarcely detectable changes are registered in the steady state levels of ATP, ADP, and $P_{i}$. How then, does one explain the fact that aldosterone will affect these parameters in open circuit or hyperpolarized bladders, but not in depolarized or reversed-polarized bladders? A reasonable answer may lie in the greatly different magnitudes of the total fluxes through the systems. In a low-flux situation (open circuit or hyperpolarization) a small increment in the rate of ATP generation would easily have a detectable effect on the steady state nucleotide levels, whereas in a high-flux situation (depolarization) the same increment in rate would represent a small increase in an already large number and might have no detectable effect.

In the present study, $\mathrm{NaCN}$ reduced ATP and ATP/ADP of bladders in open circuit. This correlated with a proportional decrease in short circuit current. Such a proportional correlation occurred irrespective of whether the ATP and ATP/ADP was increased by aldosterone or decreased by different concentrations of $\mathrm{NaCN}$ (Figs. 7 and 8 ).

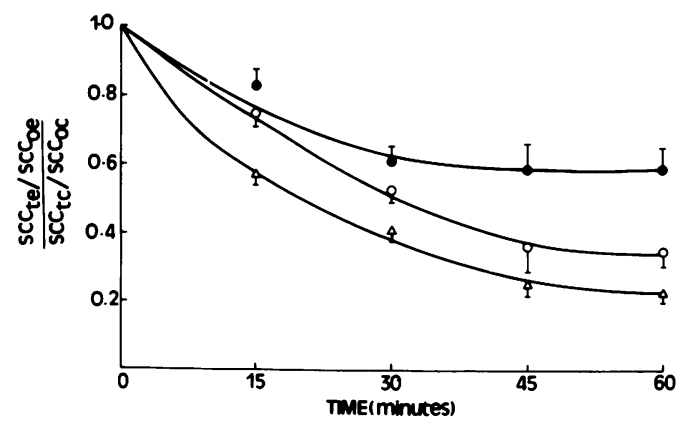

Figure 5. Short circuit current response to $\mathrm{NaCN} 100 \mu \mathrm{M}(\bullet)(n$ $=6), 250 \mu \mathrm{M}(O)(n=6)$, and $500 \mu \mathrm{M}(\Delta)(n=6)$ in time. The points represent the mean \pm SEM. 
Table II. Mean Values for Adenine Nucleotides and $P_{i}$ of Control $(C)$ and Aldosterone-treated $(E)$ Hemibladders at Different Voltage Clamping

\begin{tabular}{|c|c|c|c|c|c|c|}
\hline & \multicolumn{2}{|c|}{ ATP* } & \multicolumn{2}{|c|}{ ADP* } & \multicolumn{2}{|c|}{$\mathbf{P}_{\mathrm{i}}^{*}$} \\
\hline & C & E & C & E & $\mathrm{C}$ & E \\
\hline$+75 \mathrm{mV}$ & $1.00 \pm 0.10$ & $0.97 \pm 0.06$ & $0.53 \pm 0.05$ & $0.51 \pm 0.05$ & $1.67 \pm 0.15$ & $1.50 \pm 0.21$ \\
\hline $0 \mathrm{mV}$ & $1.01 \pm 0.07$ & $1.04 \pm 0.04$ & $0.52 \pm 0.02$ & $0.55 \pm 0.02$ & $1.55 \pm 0.12$ & $1.46 \pm 0.10$ \\
\hline $\begin{array}{l}\text { Open circuit } \\
-90 \mathrm{mV}\end{array}$ & $0.87 \pm 0.03$ & $1.03 \pm 0.03 \ddagger$ & $0.51 \pm 0.03$ & $0.42 \pm 0.02 \ddagger$ & $1.72 \pm 0.12$ & $1.44 \pm 0.16$ \\
\hline$-150 \mathrm{mV}$ & $0.96 \pm 0.02$ & $1.11 \pm 0.03 \ddagger$ & $0.53 \pm 0.03$ & $0.48 \pm 0.02 \S$ & $1.52 \pm 0.16$ & $1.05 \pm 0.11$ \\
\hline
\end{tabular}

* Values are expressed as micromoles per $100 \mathrm{mg}$ proteins. $\ddagger$ Significantly different from control values $P<0.01$. $\S$ Significantly different from control values $P<0.05$.

Prednisolone had no effect on sodium transport nor on the adenine nucleotide levels. Amiloride, known to inhibit sodium entry at the apical membrane, was associated with larger increase in ATP in response to aldosterone. These results demonstrate clearly that there is some relationship between the total cellular ATP level or the cellular ATP/ADP ratio and the rate of sodium transport: When cyanide is present, they both decline; when aldosterone is present, they both increase. The exact definition of the mechanism responsible for this relationship will not be possible until more is known about the intracellular distribution and binding of the nucleotides. The finding that much of intracellular ADP may be in a bound form, not readily available for reaction (36), might also apply to ATP to some degree, and the fact that the cellular ATP concentration greatly exceeds the reported $K_{\mathrm{m}}$ for the transport ATP-ase system implies that any dependence of the system on the ATP level results from some kind of compartmentalization. Saito et al. (37), approaching this question through the formalism of linear nonequilibrium thermodynamics and using the formula $\mathrm{A}=-$ short circuit current/(Jr/dPD), where $A$ is the affinity of the metabolic reaction that is equivalent to the negative Gibbs free energy change $-(\Delta G)$

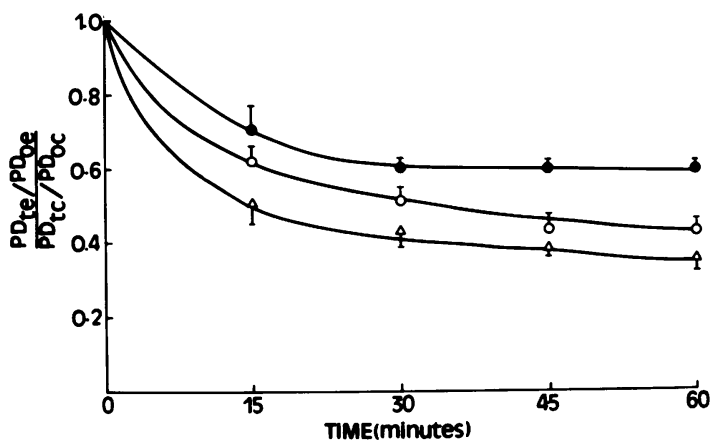

Figure 6. Potential difference response to $\mathrm{NaCN} 100 \mu \mathrm{M}(\bullet)(n=6)$, $250 \mu \mathrm{M}(O)(n=6)$, and $500 \mu \mathrm{M}(\Delta)(n=6)$ in time. The points represent the mean \pm SEM. and $\mathrm{Jr}$ is the rate of oxygen consumption, found that $\mathrm{A}$ increased 2.5-fold after aldosterone. A further increase of $50 \%$ above control level was obtained after amiloride. Our results using a biochemical approach confirm both these changes. The dependence of oxygen consumption on PD, which was abolished by ouabain in the presence or absence of aldosterone reflects that the changes are a function of the active transport system rather than those of other aspects of tissue metabolism (37). Deweer (38) proposed that a change in ATP/ADP produced by a decrease in ADP will favor Na-K exchange through the pump in preference to $\mathrm{Na}-\mathrm{Na}$ exchange. Park and Edelman (39) showed that aldosterone irrespective of sodium concentration increased the inhibition constant $K_{\mathrm{i}}$ for amiloride but decreased the $K_{\mathrm{i}}$ for ouabain. Since the response of sodium transport to a gradual increase in mucosal sodium concentrations was enhanced by aldosterone while Na-K-ATPase remained constant $(12,13)$ they concluded that an increase in ATP through a variety of mechanisms that involve phosphorylation was responsible for the change in per-

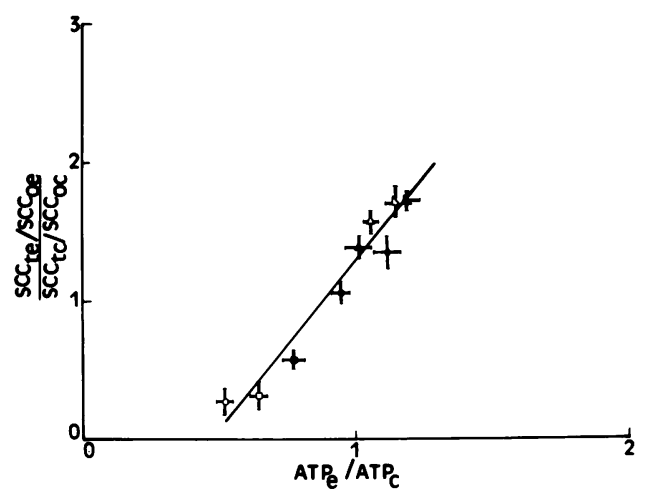

Figure 7. Short circuit current ratio (mean \pm SEM) as a function of change in (ATPe/ATPc) (mean \pm SEM), following $100 \mathrm{nM}$ aldosterone at $180 \min (\Delta)(n=15), 240 \min (\Delta)(n=10), 120 \min (\Delta)(n$ $=11), 75 \mathrm{~min}(\Delta)(n=6)$, and $150 \mathrm{~min}(\diamond)(n=6)$; following diluent (control) $(\bullet)(n=5)$; following $\mathrm{NaCN} 100 \mu \mathrm{M}(\square)(n=6)$ $250 \mu \mathrm{M}(\square)(n=6)$, and $500 \mu \mathrm{M}(0)(n=6)$. The $\mathrm{NaCN}$ and 150 min aldosterone experiments were done in a different batch of toads 12-18 mo later. The $150 \mathrm{~min}$ aldosterone experiments had prednisolone as control. $r=0.96, P<0.001$. 


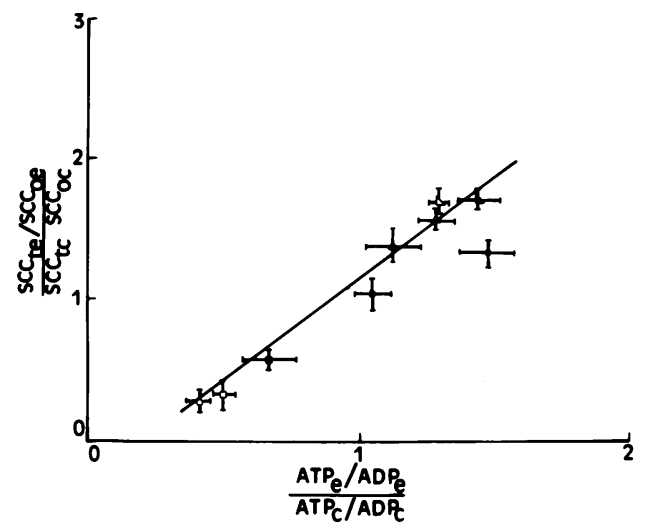

Figure 8. Short circuit ratio (mean \pm SEM) as a function of change in $(\mathrm{ATP} / \mathrm{ADP})_{\mathrm{c}} /(\mathrm{ATP} / \mathrm{ADP})_{\mathrm{c}}$ (mean \pm SEM), following $100 \mathrm{nM}$ aldosterone at $180 \mathrm{~min}(\square)(n=15), 240 \mathrm{~min}(\square)(n=10), 120 \mathrm{~min}$ $(\Delta)(n=11), 74 \min (\Delta)(n=6)$, and $150 \min (\diamond)(n=6)$; following diluent (control) $(\bullet)(n=5)$; following $\mathrm{NaCN} 100 \mu \mathrm{M}(\boldsymbol{\square})$ $(n=6), 250 \mu \mathrm{M}(\square)(n=6)$, and $500 \mu \mathrm{M}(0)(n=6)$. The $\mathrm{NaCN}$ and $155 \mathrm{~min}$ aldosterone experiments were done in a different batch of toads 12-18 mo later. The 150-min aldosterone experiments had prednisolone as control. $r=0.95, P<0.001$.

meability in addition to its effect on the turnover rate of the pump.

Recently, Palmer et al. (40), using the technique of nearinstantaneous current voltage relationships $(41,42)$, extended this observation and showed that aldosterone, after AIP synthesis, produced an ATP-dependent recruitment of preexisting sodium channels into the apical membrane. The $K_{\mathrm{m}}$ of this process for ATP is not determined and may be high, which makes the assumption of compartmentalization unnecessary. Despite these uncertainties, some deductions may be made from the fact that changes in ATP and ATP/ADP produced by $\mathrm{NaCN}$ or aldosterone correlated with changes in the rate of transport. First, the action of cyanide is well known. It inhibits respiration directly and thereby slows the rate of ATP generation, which effect is obvious from the decline in the measured ATP. The correlated decline in sodium transport demonstrates that cyanide is resulting in decreased ATP availability to the transport system, whatever the mechanism. A primary inhibition of the transport system by cyanide would cause the opposite effect, i.e., an increase in ATP as is shown in amiloride-treated bladders. Second, the action of aldosterone is not well known, but its general effect may be deduced, since it does not only increase both ATP and transport, it increases them in a ratio which is precisely related to the decrease caused by cyanide (Figs. 7 and 8). This implies that aldosterone is doing the reverse, namely increasing the distribution of ATP to the transport system. Again, a primary effect of aldosterone on the transport system would have been reflected by decrease in ATP resulting from a stimulated hydrolysis.

It is apparent that we are dealing here with effects mediated through the energy-supplying side of the cycle, and that the transporting side of the cycle is responding passively. Effects mediated through the transporting side, brought about by directly manipulating the rate of transport with variation in the ionic gradients have been extensively analyzed (43) and not unexpectedly show the opposite kind of correlation with nucleotide levels. Thus, a primary stimulation of transport will decrease the $-\triangle$ GATP by accelerating hydrolysis of ATP, where as an inhibition of generation would also decrease $-\triangle \mathrm{GATP}$ but would inhibit transport.

To summarize our views, which are admittedly speculative, we believe that the primary effect of aldosterone is on ATP generation, leading to increased utilization. An increase in steady state ATP levels in association with this change can only be observed when the pump is "idling" or nearly so, i.e., when flux through the pump pathway is low or nil, because utilization keeps pace with generation when flux is high. Amiloride, by contrast, uncouples ATP generation from ATP utilization, thereby leading to a higher steady state level of ATP. Cyanide primarily reduces ATP generation, which secondarily reduces transport. The slope of these decrements (Fig. 8) is the same as the slope of the aldosterone-induced increments.

In conclusion, these results support the view that the stimulatory effects of aldosterone on sodium transport involve an increase in ATP and/or $(\mathrm{ATP}) /(\mathrm{ADP}) \times\left(\mathrm{P}_{\mathrm{i}}\right)$. The mechanisms involved are still under investigation.

\section{Acknowledgments}

The authors would like to thank Drs. Mackenzie Walser and Elmon Coe for valuable comments.

This work was supported by a grant from the Lebanese Research Council (38-5758) and the American University of Beirut Faculty Practice Plan Research Fund (18-5227).

\section{References}

1. Crabbé, J. 1961. Stimulation of active sodium transport by the isolated toad bladder with aldosterone in vitro. J. Clin. Invest. 40:21032110.

2. Edelman, I. S., R. Bogoroch, and G. H. Porter. 1963. On the mechanism of action of aldosterone on sodium transport: the role of protein synthesis. Proc. Natl. Acad. Sci. USA. 50:1167-1177.

3. Fanestil, D. D., and I. S. Edelman. 1966. On the mechanism of action of aldosterone on sodium transport: effects of inhibition of RNA and protein synthesis. Fed. Proc. 25:912-916.

4. Majundar, A. P. N., and D. T. Trachewsky. 1971. Protein synthesis by ribosomes from rat kidney cortex: effect of aldosterone and bilateral adrenalectomy. Can. J. Biochem. 49:501-509.

5. Scott, W. N., and V. S. Sapirstein. 1975. Identification of aldosterone induced proteins in the toad urinary bladder. Proc. Natl. Acad. Sci. USA. 72:4056-4060.

6. Sharp, G. W. G., and A. Leaf. 1966. Mechanism of action of aldosterone. Physiol. Rev. 46:593-633.

7. Handler, J. S., A. S. Preston, and J. Orloff. 1972. Effect of aldosterone on the sodium content and energy metabolism of epithelial cells of the toad urinary bladder. J. Steroid Biochem. 3:137-141. 
8. Civan, M. M., and R. E. Hoffman. 1971. Effects of aldosterone on electrical resistance of toad bladder. Am. J. Physiol. 220:324-328.

9. Lipton, P., and I. S. Edelman. 1971. Effects of aldosterone and vasopressin on electrolytes of toad bladder epithelial cells. Am. J. Physiol. 221:733-741.

10. Goodman, D. P., J. E. Allen, and H. Rasmussen. 1969. On the mechanism of action of aldosterone. Proc. Natl. Acad. Sci. USA. 64:330337.

11. Hill, J. H., N. Cortas, and M. Walser. 1973. Aldosterone action on sodium and potassium activated adenosine triphosphatase in toad bladder. J. Clin. Invest. 52:185-189.

12. Cortas, N., and M. Walser. 1971. (Na-K) activated ATP-ase in isolated mucosal cells of toad bladder. Biochim. Biophys. Acta. 249:181187.

13. Edelman, I. S. 1979. Mechanisms of action of aldosterone: energetic and permeability factors. $J$. Endocrinol. $81: 49$ p-53p.

14. Edelman, I. S., and D. D. Fanestil. 1970. Mineralocorticoids. In Biochemical Actions of Hormones. Academic Press, New York. 1:321364.

15. Fimognari, G. M., G. H. Porter, and I. S. Edelman. 1967. The role of tricarboxylic acid cycle in the action of aldosterone on sodium transport. Biochim. Biophys. Acta. 135:89-99.

16. Edelman, I. S. 1968. Regulatory Function of Biological Membranes. Elsevier/North Holland, Amsterdam. 117-194.

17. Kirsten, E., R. Kirsten, A. Leaf, and G. W. G. Sharp. 1968. Increased activity of enzymes of the tricarboxylic acid cycle in response to aldosterone in the toad bladder. Pfluegers Arch. 300:213-225.

18. Kirsten, E., R. Kirsten, and A. Salibian. 1972. A study on the effect of aldosterone on the extramitochondrial adenine nucleotide system in rat kidney. J. Steroid Biochem. 3:173-179.

19. Kirsten, E., and R. Kirsten. 1972. Redox state of pyridine nucleotides in renal response to aldosterone. Am. J. Physiol. 223(1):229235.

20. Handler, J. S., A. S. Preston, and J. Orloff. 1969. The effect of aldosterone on glycolysis in the urinary bladder of the toad. J. Biol. Chem. 244:3194-3199.

21. Cortas, N., A. Mooradian, E. Abras, and M. Walser. 1981. The response to aldosterone of toad and turtle bladder is associated with changes in adenine nucleotide levels. American Society of Nephrology. 143A. (Abstr.)

22. Cortas, N., E. Abras, and M. Walser. 1983. Aldosterone response in the turtle bladder is associated with an increase in ATP. Am. J. Physiol. In press.

23. Walser, M. 1969. Reversible stimulation of sodium transport in the toad bladder by stretch. J. Clin. Invest. 48:1714-1723.

24. Walser, M. 1972. Components of sodium and chloride flux across toad bladder. Biophys. J. 12:351-368.

25. Ussing, H. H., and K. Zerahn. 1951. Active transport of sodium as the source of electric current in the short circuited isolated frog skin. Acta Physiol. Scand. 23:110-127.
26. Fawaz, G., and E. Fawaz. 1971. Methods in pharmacology. Appleton-Century-Crofts, New York. 1:515-551.

27. Fiske, C. H., and Y. Subbarow. 1925. The colorimetric determination of phosphorus. J. Biol. Chem. 66:333-345.

28. Layne, E. 1957. Spectrophotometric and turbidimetric methods for measuring proteins. Methods Enzymol. 3:447-454.

29. Porter, G. H., and I. S. Edelman. 1964. The action of aldosterone and related corticosteroids on sodium transport across the toad bladder. J. Clin. Invest. 43:611-620.

30. Sharp, G. W. G., and A. Leaf. 1964. Biological action of aldosterone in vitro. Nature (Lond.). 202:1185-1188.

31. Snart, R. S., and J. F. Wheldrake. 1980. Effects of saline exposure on the response of toad bladder (Bufo marinus) to aldosterone. Biochim. Biophys. Acta. 631:104-111.

32. Garland, H. O., and I. W. Henderson. 1975. Influence of environmental salinity on renal and adrenocortical function in the toad, Bufo Marinus. Gen. Comp. Endocrinol. 27:136-143.

33. Gfeller, E., F. Ferris, and M. Walser. 1971. The effects of electrically induced changes in $\mathrm{Na}$ transport on width of lateral spaces in toad bladder epithelium. Fed. Proc. 30:421.

34. Bobrycki, V. A., J. W. Mills, A. D. C. MacKnight, and D. R. Dibona. 1981. Structural responses to voltage clamping in the toad urinary bladder. I. The principal role of granular cells in the active transport of sodium. J. Membr. Biol. 60:21-23.

35. Vieira, F. L., S. R. Caplan, and A. Essig. 1972. Energetics of sodium transport in frog skin. I. Oxygen consumption in the short circuited state. J. Gen. Physiol. 59:60-76.

36. Veech, R. L., J. W. R. Lawson, N. W. Cornell, and H. A. Krebs. 1979. Cytosolic phosphorylation potential. J. Biol. Chem. 254:65386547.

37. Saito, T., A. Essig, and S. R. Caplan. 1973. The effect of aldosterone on the energetics of sodium transport in the frog skin. Biochim. Biophys. Acta. 318:371-382.

38. Deweer, P. 1970. Effects of intracellular adenosine-5'-diphosphate and orthophosphate on the sensitivity of sodium efflux from squid axon to external sodium and potassium. J. Gen. Physiol. 56:583-620.

39. Park, C. S., and I. S. Edelman. 1980. Dual action of aldosterone on $\mathrm{Na}$ transport across toad urinary bladder: $\mathrm{Na}$-permeability and $\mathrm{Na}$ pump. Fed. Proc. 39(1):492.

40. Palmer, L. G., J. H. Y. Li, B. Lindemann, and I. S. Edelman 1982. Aldosterone control of the density of sodium channels in the toad urinary bladder. J. Membr. Biol. 64:91-102.

41. Palmer, L. G., I. S. Edelman, and B. Lindemann. 1980. Currentvoltage analysis of apical sodium transport in toad urinary bladder. Effects of inhibitors of transport and metabolism. J. Membr. Biol. 57:5971.

42. Fuchs, W., E. H. Larsen, and B. Lindemann. 1977. Current voltage curve of sodium channels and concentration dependance of sodium permeability in frog skin. J. Physiol. (Lond.). 267:137-166.

43. Dixon, T. E., and Q. Al-Awqati. 1980. $\mathrm{H}^{+} /$ATP stoichiometry of proton pump of turtle urinary bladder. J. Biol. Chem. 255:32373239. 